\title{
Measuring Impact of Traffic Parameters in Adaptive Signal Control through Microscopic Simulation
}

\author{
Fatin 'Ayuni Bt Aminzal ${ }^{1}$ \\ Faculty of Civil Engineering and Built Environment \\ Universiti Tun Hussein Onn Malaysia \\ Batu Pahat, Malaysia, 86400
}

\author{
Munzilah Binti Md Rohani \\ Associate Professor \\ Faculty of Civil Engineering and Built Environment \\ Universiti Tun Hussein Onn Malaysia \\ Batu Pahat, Malaysia, 86400
}

\begin{abstract}
This paper aims to exploit the traffic parameters setting in adaptive traffic control. In this study, is known as Dynamic Timing Optimiser (DTO). DTO is an online algorithm, uses real-time optimisation in estimating cycle length according to fluctuations arrival flow registered from the detector. DTO cycle time estimation is also incorporated with preset parameters including saturation flow rate (s) and lost time (L). However, these traffic flow parameters commonly inputted as one deterministic value which adopted for the whole day. For example, presumed constant of saturation flow rate (s) do not accurately represent an actual oversaturated condition. The effects of employing inaccurate saturation flow rate (s) lead to the underestimation of cycle length. Therefore, a set of parameters value is applied and tested encompass of default value and adjusted value that implied a heaviest traffic condition through microscopic simulation. This resulted in outcomes of intersection performance in terms of intersection delay, travel time and throughput. According to simulation result, saturation flow rate (s) parameters show a great influence in cycle length optimisation compared to lost time (L) parameter. Employing a realistic saturation flow rate (s) while inputting parameters in DTO according to real traffic conditions contribute to a less intersection delay. In addition, the study revealed that a longer lost time $(\mathrm{L})$ configured in the signal system, a longer cycle length generated by DTO algorithm. As predicted, high delay occurs during long cycle length yet benefited in allowing a higher throughput.
\end{abstract}

Keywords-Adaptive signal control; optimal cycle length; saturation flow rate; lost time; microsimulation

\section{INTRODUCTION}

Dynamic Timing Optimiser (DTO) cycle length model has been developed to produce an optimal cycle length in realtime traffic condition. DTO is an adaptive signal control system implemented in Malaysia mainly in Kuala Lumpur City Centre. During installation of DTO, two traffic parameters setting were identified in DTO cycle length model; saturation flow rate (s) and lost time (L).

Saturation flow rate (s) is defined as vehicle queue discharge at a more or less constant rate during effective green [1]. Saturation flow rate (s) can be measured from site by collecting similar vehicle headway after four of five vehicles depart from stop line, or about 10 seconds after the start of green period [2]. Calculation of saturation flow rate (s) can be measured by averaging saturation headway (h) in the field as summarised in Eq. 1 [3].

$S=\frac{3,600}{h}$

Where $\mathrm{s}=$ saturation flow rate, 3,600 = number of seconds per hour and $\mathrm{h}=$ saturation headway.

Generally, vehicle headway is varying according to site condition, including speed limit, gradient of the intersection and number of through lanes [4]. A reduced saturation flow rate resulted a longer cycle length [5]. For the cycle length estimation in fixed time control, Highway Capacity Manual has suggested a standard saturation flow rate is fixed to 1,900 pcu/hour/lane [6].

Another traffic parameters involved in optimising cycle length by DTO is a lost time (L) in regards to the total of signal phasing. The estimation of lost time (L) is crucial in determining optimal cycle length. Lost time estimation methods that has been distinguished by USA, Japan, Germany and Australia is equal to the sum of the intergreen times (I) [7]. An increasing of lost time may effects on the increasing of optimal cycle length, and as a consequences, the intersection delay increases [8].

The traffic parameters in DTO is structured to be configured as one deterministic value which adopted for the whole day without differentiate off-peak and highest peak condition. Engineers are typically inputted an average value to applied during all day. As explained on above, saturation flow rate (s) presumed constant do not accurately represent an actual oversaturated condition. In addittion, a small variation of lost time may lead to inaccurate calculation of cycle length [9]. Therefore, saturation flow rate need to be calibrated particularly when demand reached the capacity [10].

This study is intended to examine a scenario if the parameters can be adjusted according to the peak condition instead of using a default value. The scenarios are basically exploting the value of 1 ) saturation flow rate of 1,714 $\mathrm{pcu} / \mathrm{hr} /$ lne and 2,250 pcu/hr/lane 2) lost time of 16s, 24s and 36s. The evaluation was conducted using vehicle flow obtained from detector, signal timing generated from DTO traffic engine and travel time collected from site survey. This research is expected to serve future reference on relationship of paramaters in cycle length model theory especially when adopted in real-time calculation of adaptive signal control. 
This paper is organised as follows. "Background" introduces on the concept of optimal cycle length and DTO adaptive control. "Methodology" briefed on the study area along with the data collection, DTO parameters configuration and microsimulation modelling process. Findings and result are presented in "Result and Discussion". Finally, "Conclusion" conclude this research study with future works explained.

\section{BACKGROUND}

Signalised intersection acquired a probabilistic calculation of cycle length. Since the beginning, there are a few cycle lengths models that are adopted in controlling the movement of vehicular traffic at intersection, for example Webster method and HCM 2000 model. Webster method estimates the green time of the phases is in the ratio of their flow ratio [11]. This can be shown in the Equation 2.

$\mathrm{C}_{0}=\frac{1.5 L+5}{1-Y}$

Where $\mathrm{C}_{0}=$ optimal minimum delay cycle length (s); $\mathrm{L}=$ total lost time within the cycle (s); and $\mathrm{Y}=$ sum of critical phase flow ratios.

In the Highway Capacity Manual 2000 document, estimation of cycle length is available in Appendix A, Chapter 10 [12].

$C=\frac{L}{1-\frac{\min (C S, R S)}{R S}}$

Where C= cycle length (s); L = total lost time (s/cycle); CS $=$ sum of the critical phase traffic volumes (veh/hr); RS = reference sum flow rate (s x PHF x fa), (veh/hr); PHF = peak hour factor; $\mathrm{s}=$ saturation flow rate and fa = area type of adjustment factor [0.90 if central business district and 1.0 for otherwise].

Eventhough the above model have been widely used at isolated pre-timed signalised intersection, they have some limitations when implemented for cycle length estimation. For example, Webster method is not applicable when the traffic condition is near-saturated or saturated condition. When the critical flow ratio is equal or more than one, the model becomes infeasible where it generates unreasonbaly large cycle length [13]. Whereas the HCM 2000 model is targeting on the expected saturation in generating their cycle length which may contributing to the augmented value [14]. Webster method is efficient use at under saturated condition and HCM 2000 model is suitable at oversaturated condition [15]. Both model were developed to suit pre-timed signal operation where the traffic pattern is well distinguish between peak hour and off peak condition.

As time and technology emerged, an adaptive traffic control has been introduced to overcome the limitations of pre-timed control. Adaptive control offered an independent strategy in calculating their signal timings according to actual traffic demand. Sena Traffic Systems Sdn Bhd (STS), a local made company in Malaysia has took the challenge in developing own adaptive signal algorithm known as Dynamic Timing Optimiser (DTO). The purpose of DTO is targeted to minimize wasting green and delay time as well as to increase

Universiti Tun Hussein Onn Malaysia (UTHM), Malaysia; Ministry of Higher Education (MOHE), Malaysia. capacity of the intersection. DTO signal control requires detector to detect vehicle passage/presence to register presence of vehicles after the termination of green in estimating next cycle green time.

In the beginning of DTO signal timing process, the realtime vehicle detection at site is transmitted to the controller. The information received by the controller is subsequently directed to a server by using a wired or wireless communication. After that, DTO algorithm performed a traffic data processing by considering dependant variables such as peak hour factor and congestion index. DTO are then doing customisation of the timing according to the algorithm decision branches that has been developed according to traffic conditions.

DTO cycle length model has incorporated a traffic parameters similar with Webster and HCM model such as saturation flow rate (s) and lost time (L). This traffic parameters are configured offline during pre-installation and applied throughout the day. This traffic parameters are essential for DTO traffic engine in providing most accurate signal timing according to the situation on site. Fig. 1 demonstrates the summary of DTO optimisation process as explained above.

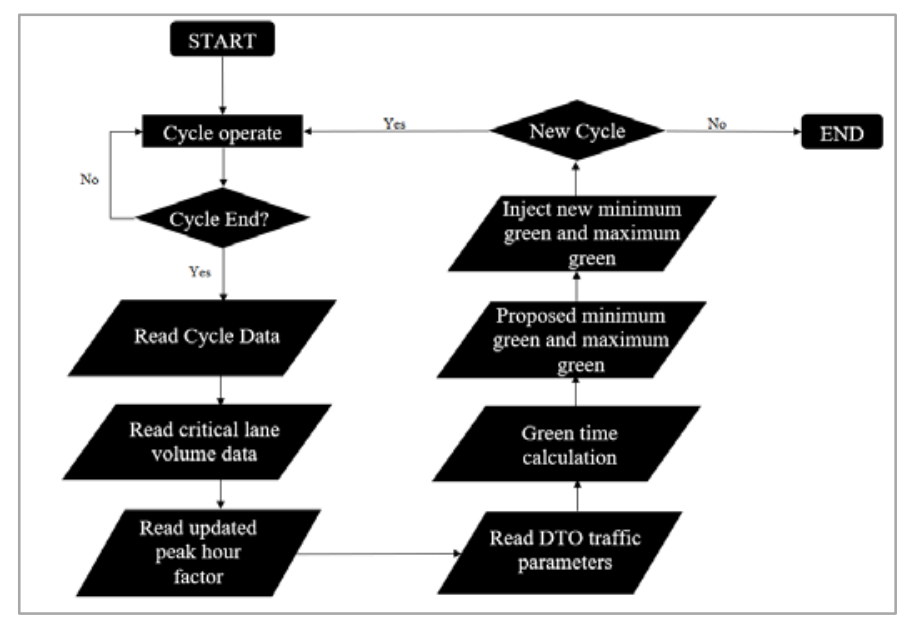

Fig. 1. Flowchart of DTO Optimisation Process.

\section{MethodOLOGY}

\section{A. Description of Study Area}

A signalised four-legged intersection has been selected as a case study to achieve the research aim. This intersection is on the four-lane dual carriageway on Jalan Jalil Perkasa 1, Kuala Lumpur. Most of the traffic traverse this sub-arterial road going towards and from KL city centre. Fig. 2 is a map showing the location of the study intersection and peak hour traffic condition.

\section{B. Field Data Collection}

Traffic volume, intersection geometry, queue length data and travel time data were obtained on typical weekday. A morning peak traffic condition were chosen as study duration as to simulate a high traffic condition. These data were used to calibrate the simulation models. 


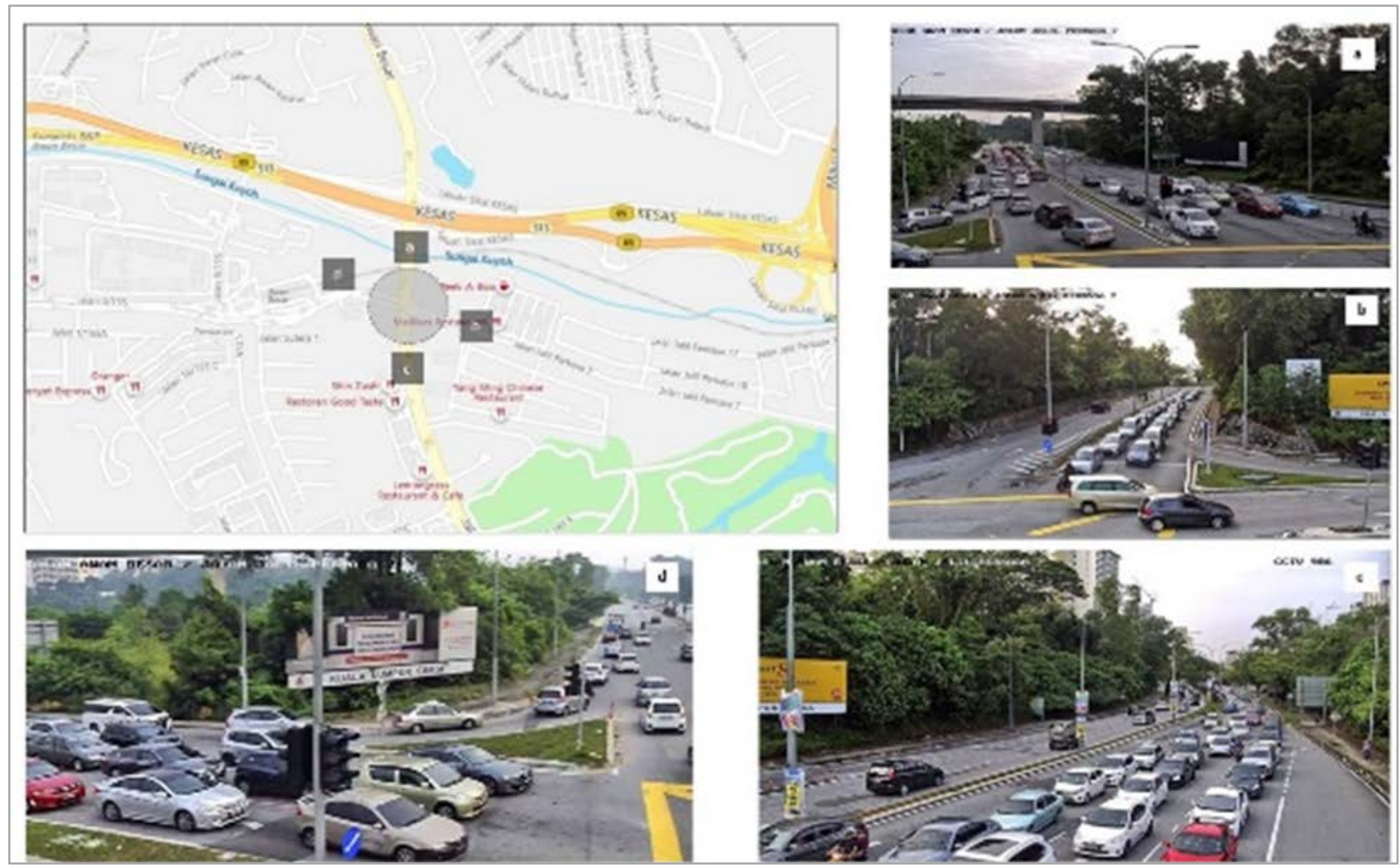

Fig. 2. Junction Location and Site Condition.

\section{- Traffic Volume}

Traffic volume from detector at stop line were obtained through STS control centre software. Highest traffic volume during morning peak between 7.00am to 10.00am has been identified. While turning movement volume and vehicle composition were collected during manual count survey. Table I tabulates the traffic volume on $8.00 \mathrm{am}$ to $9.00 \mathrm{am}$. It is noted the traffic composition during morning peak hour dominated by car (98.2\%), medium lorries (1.3\%) and busses $(0.5 \%)$.

\section{- Intersection Geometry}

The geometric data were extracted from Google Earth and validated by field measurement. The entry approach lane width and short lane length were identified. Fig. 3 show the existing layout of the intersection.

\section{- Queue Length and Travel Time}

The maximum queue was identified based on speed profile particularly at southbound approach. The selection of this direction is due to the high traffic volume from this approach. The vehicle is consider in a queue state when the speed is below than $10 \mathrm{~km} / \mathrm{hr}$. While travel time survey was estimated using floating car technique in a test vehicle. This survey is conducted by traverse from start at end point of the defined segment from southbound approach. Travel time within segment was determined based on the average of seven runs of a floating car. Fig. 4 shows a typical identified queue length based on speed profile.
TABLE I. TRAFFIC VolUME OF Site StUdy (VEH/HR)

\begin{tabular}{|l|l|l|l|}
\hline \multirow{2}{*}{ Approaches } & \multicolumn{3}{|l|}{ Traffic Volume (veh/hr) } \\
\cline { 2 - 4 } & LT & TM & RT \\
\hline Westbound & 464 & 191 & 251 \\
\hline Northbound & 101 & 389 & 243 \\
\hline Eastbound & 55 & 248 & 213 \\
\hline Southbound & 237 & 1268 & 312 \\
\hline Total Throughput & 3,926 \\
\hline
\end{tabular}

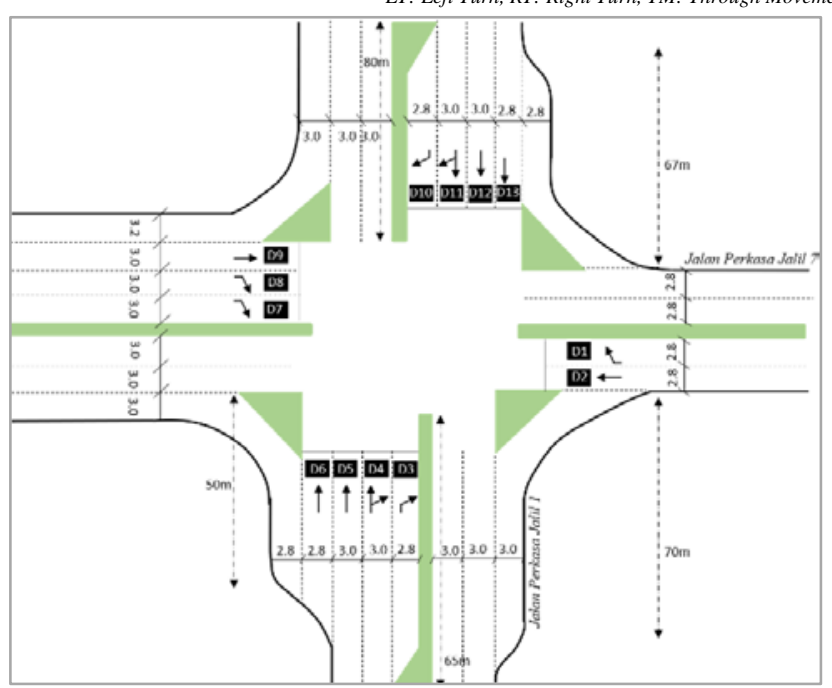

Fig. 3. Intersection Geometry. 


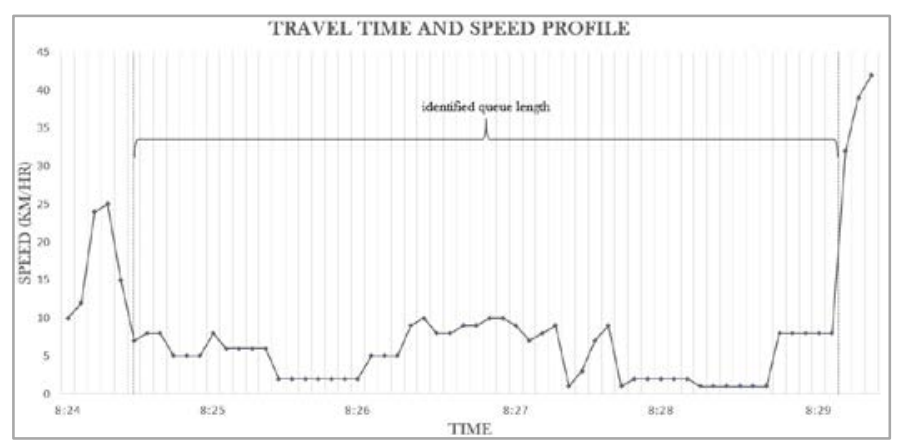

Fig. 4. Travel Time and Speed Profile.

\section{DTO Parameters Impact}

DTO parameters effect towards intersection performance was investigated by employing different value of saturation flow rate (s), lost time (L) and number of stages (n). As part of the simulation test, a value of 2,250 saturation flow rate is adopted by using a vehicle headway of 1.6s to interpret more aggressiveness of the driver on site during rush hour. This value is obtained from averaging of vehicle headway after four or five vehicles depart from stop line at site. In current configuration, the vehicle headway of $2.1 \mathrm{~s}$ is adopted for all peak periods.

The intergreen value of existing configuration consist of $2 \mathrm{~s}$ of amber and $2 \mathrm{~s}$ of all-red. For the simulation test, a value of $4 \mathrm{~s}$ amber and $2 \mathrm{~s}$ that sum up to $6 \mathrm{~s}$ intergreen is adopted. A longer of intergreen allow vehicle at a distance longer stopping distance allow vehicle to stop comfortably. As mentioned in previous chapter, intergreen value is directed impact of lost time in DTO cycle time calculation.

Besides of DTO parameters abovementioned, the number of signal phasing configuration is impacted on total lost time. The more signal phasing, the higher of total lost time in one cycle. To investigate lost time parameters interaction, existing signal phasing from four stages is configured to be 6 stages. As the number of stages are critical in specifying total lost time, splitting right turn movement and through movement in separate exclusive phase is needed. This overlapping phase is implemented at northbound-southbound (through movement) and eastbound-westbound (right turn) approach. Fig. 5 shows the phase diagram of 6 stages and adjusted value of intergreen time and saturation flow rate.

\section{Microsimulation Modelling}

\section{- Model Development}

The existing four-legged intersection were modelled based on the heaviest peak traffic condition. The Bing Maps available in the VISSIM were used as a background over which the road links and connectors were drawn. Traffic demands and vehicle routing were inputted in the VISSIM. A data collection points, travel time segment and node were defined in the VISSIM.

\section{- Model Calibration}

Model calibration is a process of ajusting microsimulation parameters included of driver behaviour characteristic to represent field conditions [16]. According to Wisconsin
Department of Transportation (WisDOT), Wiedemennn $74 \mathrm{car}$ following model is preferred to use at urban arterial road [17]. A lower roadway capacity in VISSIM resulted by using higher values of average standstill, additive part of safety distance and multpilcative part of safety distance.

- Model Validation

Validation can be defined as a process to determine the accuracy representation of the model with site condition. A quantitative comparison simulation model output and field observed output can be measure by using a statistical validation [18]. For this study, Root Mean Squared Percentage Error (RMSPE) is applied to penalize large error at higher rate [19]. Statistical measure of RMSPE can be expressed as below.

$\mathrm{RMSPE}=\sqrt{\frac{1}{N}} \sum_{i=1}^{N}\left(\frac{M i-O i}{O i}\right)^{2}$

Where $\mathrm{N}=$ number of samples, $\mathrm{M}=$ modeled value, $\mathrm{O}=$ observed value.

Output from link volume at stop line and travel time at identified segment were compared with field data. The model is considered validated if the RMSPE value is less than $5 \%$ [20].

\section{- Simulation Run Design}

The simulation run need to meet a purpose of evaluating DTO cycle length model off using a different DTO parameters value compared to based value from existing junction configuration. Therefore, six (6) scenarios were designed and summarised in Table II. All the simulation runs of each with a different random seed number were performed for 4500 simulation seconds. This simulation period included of 15minutes warming up simulation period.

\begin{tabular}{|c|c|c|c|c|c|c|}
\hline & 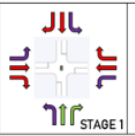 & 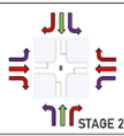 & 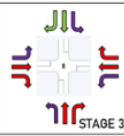 & 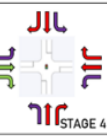 & 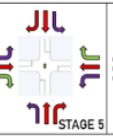 & JIL \\
\hline Phase & $C, D$ & $D, H$ & $G, H$ & $\mathrm{E}, \mathrm{F}$ & $E, A$ & $A, B$ \\
\hline Intergreen, I & $6 s$ & $6 s$ & $6 s$ & $6 s$ & $6 s$ & $6 s$ \\
\hline $\begin{array}{l}\text { Adopted } \\
\text { Saturation } \\
\text { Flow Rate, } s\end{array}$ & \multicolumn{6}{|c|}{$2,250 \mathrm{veh} / \mathrm{hr} / \mathrm{ln}$} \\
\hline
\end{tabular}

Fig. 5. Adjustment Signal Configuration of Study Site.

TABLE II. SIMULATION SCENARIO DESIGN

\begin{tabular}{|l|l|l|l|l|}
\hline Scenario & $\begin{array}{l}\text { Sat. } \\
\text { Flow Rate, } s\end{array}$ & Intergreen, $I$ & $\begin{array}{l}\text { No. } \\
\text { of Stage, } n\end{array}$ & $\begin{array}{l}\text { Total Lost } \\
\text { Time, } L\end{array}$ \\
\hline $\begin{array}{l}\text { Base } \\
\text { Model }\end{array}$ & 1,714 & 4 & 4 & 16 \\
\hline 1 & 2,250 & 4 & 4 & 16 \\
\hline 2 & 1,714 & 6 & 4 & 24 \\
\hline 3 & 2,250 & 4 & 6 & 24 \\
\hline 4 & 1,714 & 6 & 6 & 36 \\
\hline 5 & 2,250 & 6 & 6 & 36 \\
\hline
\end{tabular}




\section{RESULTS}

\section{A. Validation Result}

In this study, a validation process involved with comparing modeled and field data in terms of throughput, travel time and maximum queue length. Throughput at each link approach were compared and presented in Fig. 6. Based on the result, the RMSPE is recorded at 0.044 which is less than threshold value. This signifies that the model is replicating site condition in terms of intersection throughput.

As mentioned on previous chapter, travel time and queue length from simulation were compared to the field survey data for validation purposes. The model considers well calibrated if the percentage of difference is less than $10 \%$ [21]. Table III tabulates field and simulation result.

\section{B. Intersection Performance}

At the end of cycle two, DTO proposed a new cycle length according to the arrival flow at stop line and parameters that has been described on previous chapter. Overall, five (5) alternative scenario of 4,500 seconds were carried out and optimal cycle length generated is shown in Fig. 7. Base model (BM) represented cycle length generated according to current configuration while SC represented an alternative scenario as described in Table II.

Based on the result, Scenario 3, Scenario 4 and Scenario 5 generate large cycle as the number of stage is increase to 6 . More number of stages contibuted to the high value of lost time. Meanwhile, Scenario 1 and Scenario 2 generates optimal cycle much similar with the existing configuration scenario.

Performance of the intersection were then evaluated in terms of average delay, travel time and throughput. Fig. 8 demostrate the intersection performance by comparing of average delay and travel time. Scenario 1 and 2 were configured in a same signal phasing $(\mathrm{n}=4)$ while Scenario 3, 4 and 5 were run in six (6) signal phasing. Based on the result, Scenario 1,3 and 5 experience less delay compared to the Scenario 2 and Scenario 5 which use an existing parameters value $(\mathrm{s}=1,714 \mathrm{veh} / \mathrm{hr} / \mathrm{ln})$. Scenario 1,3 and 5 use a higher value of saturation flow rate (s) to indicates the close headway between vehicle during saturated conditions $(s=2,250$ $\mathrm{veh} / \mathrm{hr} / \mathrm{ln})$.

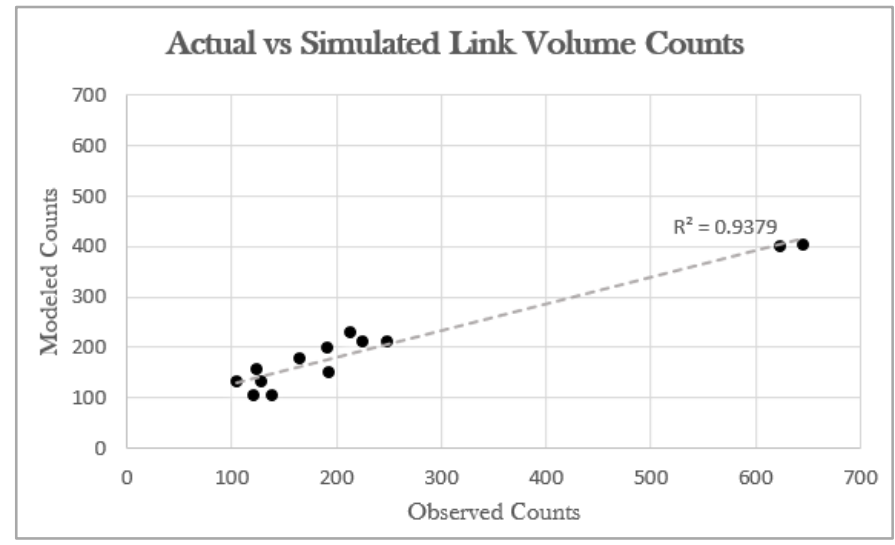

Fig. 6. Optimal Cycle Length Generated by DTO.

TABLE III. COMPARISON OF FIELD AND SIMULATION RESULT

\begin{tabular}{|l|l|l|}
\hline \multirow{2}{*}{ Parameters } & \multicolumn{2}{|l|}{ Data Obtained } \\
\cline { 2 - 3 } & Field & Simulation \\
\hline Travel Time (s) & 280.00 & 301.67 \\
\hline Maximum Queue Length (m) & 522.19 & 504.52 \\
\hline
\end{tabular}

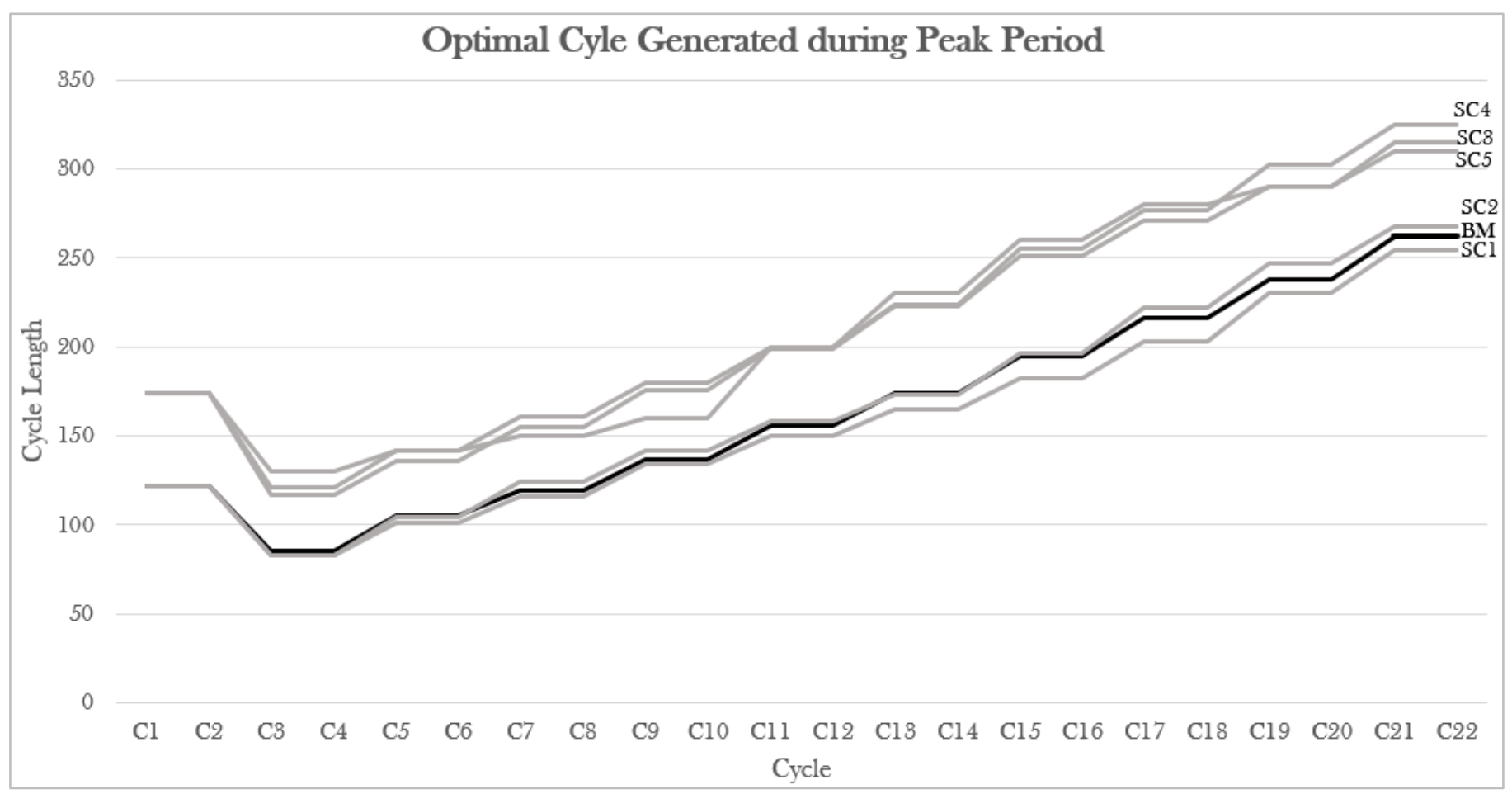

Fig. 7. DTO Optimal Cycle Result. 


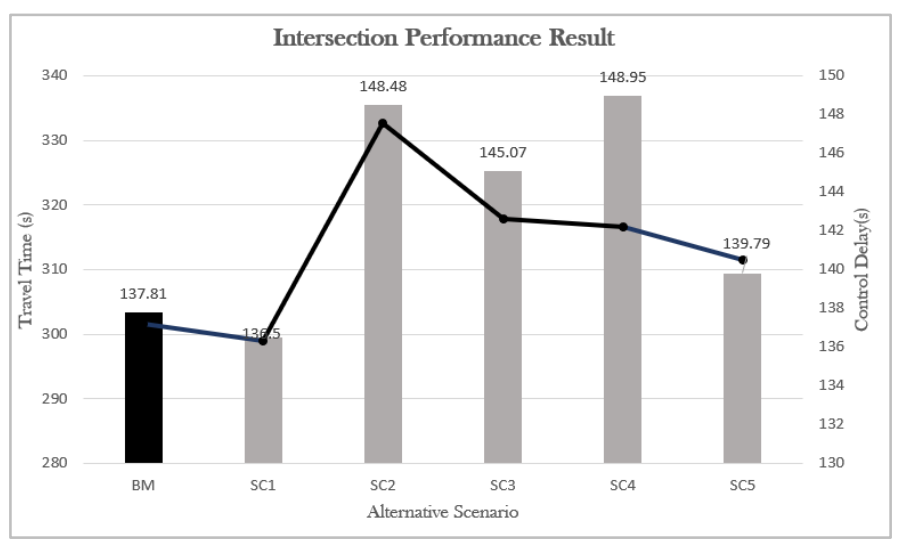

Fig. 8. Intersection Performance Result.

Meanwhile, Scenario 1 has shown a shorten travel time and control delay compared to other scenario included the base model. Scenario 4 experienced a larger delay while Scenario 2 experienced a longer travel time. Both scenario were used a saturation flow rate of $1,714 \mathrm{veh} / \mathrm{hr} / \mathrm{ln}$ with different signal phasing.

Considering the variability of delay, throughput and average queue length obtained from this study, reliable parameters in DTO should be selected to improve LOS of signalized intersections at study site. It should be noted as HCM highlighted that, the mean control delay is the primary performance measure for signalized intersection. Therefore, Scenario 1 has shown a significant impact to the intersection performance by inputting an appropriate saturation flow rate (s).

Table IV present the maximum throughput, maximum queue length and level of service of each approaches.

Based on the result tabulated in Table IV, Scenario 5 recorded a highest vehicle throughput followed by Scenario 1 . Scenario 5 used a highest saturation flow rate (s) and lost time (L) in generating optimal cycle length. This parameter has impacted on generating a longer cycle length in which to allow more vehicle to cross the intersection.

TABLE IV. INTERSECTION PERFORMANCE

\begin{tabular}{|c|c|c|c|c|}
\hline Approach & Approach Delay & Approach LOS & Approach Maximum Throughput & Average Queue Length (m) \\
\hline \multicolumn{5}{|l|}{ Scenario 1} \\
\hline Northbound & 69.62 & D & 686 & 86.18 \\
\hline Eastbound & 130.77 & $\mathrm{~F}$ & 485 & 105.93 \\
\hline Westbound & 84.17 & $\mathrm{~F}$ & 883 & 94.78 \\
\hline Southbound & 136.19 & $\mathrm{~F}$ & 1,089 & 438.58 \\
\hline Total & & $\mathrm{F}$ & 3,143 & \\
\hline \multicolumn{5}{|l|}{ Scenario 2} \\
\hline Northbound & 102.87 & $\mathrm{~F}$ & 686 & 82.91 \\
\hline Eastbound & 136.63 & $\mathrm{~F}$ & 497 & 129.00 \\
\hline Westbound & 99.12 & $\mathrm{~F}$ & 904 & 91.17 \\
\hline Southbound & 144.77 & $\mathrm{~F}$ & 999 & 434.36 \\
\hline Total & & $\mathrm{F}$ & 3,086 & \\
\hline \multicolumn{5}{|l|}{ Scenario 3} \\
\hline Northbound & 73.74 & $E$ & 689 & 84.00 \\
\hline Eastbound & 82.23 & $\mathrm{~F}$ & 496 & 91.55 \\
\hline Westbound & 97.48 & $\mathrm{~F}$ & 879 & 80.58 \\
\hline Southbound & 177.05 & $\mathrm{~F}$ & 1,050 & 436.24 \\
\hline Total & & $\mathrm{F}$ & 3,114 & \\
\hline \multicolumn{5}{|l|}{ Scenario 4} \\
\hline Northbound & 78.4 & $\mathrm{~F}$ & 689 & 78.88 \\
\hline Eastbound & 97.64 & $\mathrm{~F}$ & 488 & 93.86 \\
\hline Westbound & 123.93 & $\mathrm{~F}$ & 839 & 130.03 \\
\hline Southbound & 160.11 & $\mathrm{~F}$ & 1,100 & 438.77 \\
\hline Total & & $\mathrm{F}$ & 3,116 & \\
\hline \multicolumn{5}{|l|}{ Scenario 5} \\
\hline Northbound & 84.95 & $\mathrm{~F}$ & 696 & 78.14 \\
\hline Eastbound & 107.01 & $\mathrm{~F}$ & 490 & 105.72 \\
\hline Westbound & 78.88 & E & 908 & 109.04 \\
\hline Southbound & 153.61 & $\mathrm{~F}$ & 1,102 & 441.17 \\
\hline Total & & $\mathrm{F}$ & 3,196 & \\
\hline
\end{tabular}


Result shown in the table indicates that most of the approach in every scenario performing at LOS F. This is evident by the long queues and higher delay at most approach.

\section{Discussion}

This study demonstarates an impact of the traffic parameters in adaptive signal control strategies as known as DTO. Two (2) parameters were introduced during preinstallation of DTO to enhance a cycle length decision.

- Employing a realistic saturation flow rate (s) while inputting parameters in DTO according to real traffic conditions contribute to a better intersection performance. Currently, DTO required one value of saturation flow rate (s) which applied during all peaks (Scenario 1).

- An appropriate saturation flow rate (s) value with extra lost time may contribute for a better intersection performance during peak period (Scenario 3 and 5).

- The intersection performance may not achieve best result if the saturation flow rate (s) were not configured higher to interpret a heavy traffic condition while more signal phasing and intergreen were configured (Scenario 4 and Scenario 2).

- Total maximum throughput is obtained during longer cycle length as more vehicle allow to cross (Scenario 3, 4 and 5). However, longer cycle length impacted on higher delay at intersection as resulted from Scenario 2. This is because Scenario 2 was not interpreting a real vehicle headway where the configuration of saturation flow rate (s) is remained as constant.

\section{CONCLUSION}

As explained in the introduction chapter, saturation flow rate (s) need to be calibrated particularly when demand reached the capacity. Based on the analysis that has been conducted, DTO optimal cycle length is effectively produced by employing a calibrated value of saturation flow rate (s). Further studies will evaluate DTO configuration to consider saturation flow rate (s) as a time-based instead of inputting an average deterministic value in the system. Since this study is part of the DTO ongoing research, intergrating real-time data of vehicle headway from analytic camera is potentially to be part of future study.

This study also discover that optimal cycle length can be produced with the interaction of lost time (L) parameter and calibrated saturation flow rate (s). If the parameters only considered of lost time (L) parameter, a longer cycle length with highest delay is expected to be produced.

\section{ACKNOWLEDGMENT}

The authors would like to thank to Research and Development Department, Sena Traffic Systems Sdn Bhd (STS) for their contribution in providing traffic data and signal configuration of the study site. Sincere thanks to the programmer in R\&D STS for designing COM API in emulating STS signal control in VISSIM.

\section{REFERENCES}

[1] Transportation Research Board. (2000). Highway Capacity Manual Chapter 10. United States of America: National Academy of Science.

[2] Khisty, C. J. (1990). Transportation Engineering An Introduction . Prentice-Hall.

[3] Shao, C.-q., \& Liu, X.-m. (2012). Estimation of Saturation Flow Rates at Signalised Intersections. Discrete Dynamics in Nature and Society.

[4] Bester, C., \& Meyers, W. (2007). Saturation Flow Rates . Proceedings of the 26th South African Transport Conference (SATC 2007), (pp. 560568). Stellenbosch, South Africa.

[5] M.Day, C. (2013). Revisiting the Cycle Length - Lost Time Question with Critical Lane Analysis. Transportation Research Record of the Transportation Research Board.

[6] Hamad, K., \& Abuhamda, H. (2015). Estimating Base Saturation Flow Rate for Selected Signalised Intersection in Doha, Qatar. Journal of Traffic and Logistics Engineering, 168-171.

[7] Tang, K., Ono, T., Tanaka, S., \& Kuwahara, M. (2012). Re-Examination of Lost Time Estimation and Intergreen Time Design for Right-Turn at Signalised Intersections in Japan. Asian Transport Studies, Volume 1, Issue 4 (2011), (pp. 412-423). Japan.

[8] Zakaria, A. Y., \& Rabia, S. I. (2016). Estimating the Minimum Delay Optimal Cycle Length based on a Time-Dependant Delay Formula. Alexandria Engineering Journal, 2509-2514.Akgungor, A. P. (2018, September). Investigating Parameter Interaction with the Factorial Design Method: Webster's Optimal Cycle Length Model. Tehnicki Vjesnik 25(Supplement 2), pp. 391-395.

[9] Webster, F. (1969). Traffic Signal Setting. Road Research Technical Paper No.39. London: Her Majesty Stationary Office.

[10] J.Chen, G. a. (2009). Study on Saturation Flow Rates for Signalised Intersections . International Conference on Measuring Technology and Mechatronics Automation, (pp. 595-601). Zhangjiajie, Hunan.

[11] Akgungor, A. P. (2018, September). Investigating Parameter Interaction with the Factorial Design Method: Webster's Optimal Cycle Length Model. Tehnicki Vjesnik 25(Supplement 2), pp. 391-395.

[12] Transportation Research Board. (2000). Highway Capacity Manual Chapter 10. United States of America: National Academy of Science.

[13] Wanjing, M., \& Xinchen, Y. (2013). Optimal Offline Cycle Length Model Based on Online Bus Priority Demand. Journal of Transportation Systems Engineering and Information Technology, 124-129.

[14] Akgungor, A. P., Yildiz, O., \& Demirel, A. (2006). A Sensitivity Analysis of the HCM 2000 Model with the Factorial Design Method. Turkish Journal of Engineering and Environmental Sciences, 259-267.

[15] DingXin Cheng, Z. Z. (2005). Development of an Improved Cycle Length Model over the Highway Capacity Manual 2000 Quick Estimation Method. Journal of Transportation Engineering.

[16] Spiegelman, C., \& Eun Sug Park, L. R. (2011). Transportation Statistics and Microsimulation. New York: Chapman and Hall/CRC.

[17] Mathew, T. V. (2014). Transportation System Engineering Chapter 16. India: Cell Transmission Model, IIT Bombay.

[18] Law, A. M., \& Kelton, W. D. (2000). Simulation Modeling and Analysis. McGraw-Hill.

[19] Balakrishna, R., Antoniou, C., Ben-Akiva, M., Koutsopoulus, H. N., \& Wen, Y. (2007). Calibration of Microscopic Traffic Simulation Models. Transportation Research Record 1999, 198-208.

[20] Wisconsin Department of Transportation (WisDOT). (2019, September). Traffic Engineering, Operations \& Safety Manual. Retrieved from State of Wisconsin Department of Transportation: https://wisconsindot.gov/ dtsdManuals/traffic-ops/manuals-and-standards/teops/16-20.pdf.

[21] Osei, K. K., Adams, C. A., Ackaah, W., \& Olver-Commey, Y. (2018). Signalisation Options to Improve Capacity and Delay at Roundabouts through Microsimulation Approach: A Case Study on Arteria; Roadways in Ghana. Journal of Traffic and Transportation Engineering, $1-13$. 